\title{
FUNKCJA NIEZAWODNOŚCI I CZAS BEZAWARYJNEJ PRACY ODPOWIADAJĄCY EKSPONENCJALNEJ INTENSYWNOŚCI USZKODZEŃ
}

\begin{abstract}
Funkcja niezawodności odgrywa w nauce o niezawodności podstawową rolę, gdyż pozwala na obliczenie prawdopodobieństwa uszkodzenia w określonym czasie $t$. Aby obliczyć funkcję niezawodności należy obliczyć całkę z funkcji intensywności uszkodzeń. W dotychczasowej praktyce obliczeń niezawodności stosowano funkcję intensywności uszkodzeń, która jest stała w czasie. Jednocześnie podaje się, że intensywność uszkodzeń nie jest stała w czasie. Najprostszy przypadek liniowej zależność funkcji intensywności uszkodzeń od czasu został już rozwiązany. Jak wskazuje wielu autorów intensywność uszkodzeń jest wykładniczą funkcją czasu. Dlatego w niniejszym artykule został przedstawiony sposób obliczeń funkcji niezawodności oraz średniego czasu bezawaryjnej pracy w przypadku, gdy intensywność uszkodzeń zmienia się w czasie wykładniczo. Rozważono trzy przypadki. Pierwszy, gdy funkcja intensywności uszkodzeń jest malejąca a potem stała w czasie. Taka zależność występuje na początku istnienia wytworu techniki. Drugi przypadek, gdy na początku funkcja intensywności uszkodzeń jest stała w czasie a następnie szybko rośnie. Taka zależność odpowiada końcowej fazie istnienia wytworu techniki. Trzeci przypadek jest połączeniem dwóch pierwszych. Jest ona malejącą na początku użytkowania, potem stała i wreszcie rosnącą, gdy czas życia wytworu techniki dobiega końca. W wyniku przeprowadzonych obliczeń uzyskano analityczne wzory na funkcję niezawodności $R$ oraz średni czas życia $T_{S}$. Wykazano, że w celu obliczenia średniego czasu życia nie trzeba ani obliczać skomplikowanych całek, ani korzystać ze specjalistycznego oprogramowania. Wystarczy w celu obliczenia odpowiedniej całki zastosować metodę trapezów i zwykły arkusz kalkulacyjny. Popełniany w tym wypadku błąd jest mniejszy od $1 \%$. Co dla inżyniera jest wystarczającą dokładnością.
\end{abstract}

Słowa kluczowe: funkcja niezawodności, czas bezawaryjnej pracy, intensywność uszkodzeń, funkcja eksponencjalna

\footnotetext{
${ }^{1}$ Leszek Opyrchał, AGH Akademia Górniczo-Hutnicza, Wydział Geodezji Górniczej i Inżynierii Środowiska, Katedra Inżynierii i Ochrony Środowiska, al. Mickiewicza 30, 30-059 Kraków, tel. 1261744 97, opyrchal@agh.edu.pl
} 


\section{Wstęp}

W ogólności funkcja niezawodności wyraża się [4] wzorem:

$$
R(t)=\exp \left(\int_{0}^{t}-\lambda(\tau) d \tau\right)
$$

gdzie: $R(t)$ - funkcja niezawodności,

$\lambda(t)$ - intensywność uszkodzeń,

$t$-czas,

$\tau$ - zmienna całkowania,

a średni czas bezawaryjnej pracy $T_{S}$ definiowany jest jako:

$$
T_{S}=\int_{0}^{\infty} R(t) d t
$$

Przy założeniu, że intensywność uszkodzeń $\lambda$ nie zależy od czasu, otrzymuje się znane wzory:

$$
R(t)=e^{-\lambda t}, \quad T_{S}=\frac{1}{\lambda}
$$

Jednakże, jak wykazuje wielu autorów [np. 7] założenie stałości w czasie funkcji intensywności uszkodzeń na ogół nie jest spełnione. W przypadku, gdy intensywność uszkodzeń, jest liniową funkcją czasu, wzory na $T(t)$ i $T_{S}$ zostały podane w [5] i na ogół nie dają wyrazić się w prostej postaci. W nauce o niezawodności szczególną rolę odgrywa wykładnicza zależność intensywności uszkodzeń od czasu, gdyż jest ona najczęściej spotykana [4] w okresie początku i końca istnienia wytworu techniki. Rozważeniu, jak w tym przypadku obliczać funkcję niezawodności oraz średni czas bezawaryjnej pracy poświęcony jest niniejszy artykuł.

\section{Typy wykładniczej funkcji intensywności uszkodzeń}

\subsection{Typ I - malejący}

Intensywność uszkodzeń może mieć charakter malejący (rys nr 1), kiedy to na początku użytkowania wytworu techniki intensywność uszkodzeń jest duża, po czym maleje i utrzymuje się na stałym poziomie. W tym przypadku funkcja intensywności uszkodzeń wyraża się wzorem: 


$$
\lambda(t)=a \cdot e^{-b t}+c
$$

gdzie: $a, b$ i $c$ są stałymi oraz $a, b, c>0$.Taki typ intensywności uszkodzeń odpowiada na przykład hydrotechnicznym budowlom piętrzącym wodę. Na rysun$\mathrm{ku} 1$ przedstawiono wykres eksponencjalnej, malejącej funkcji intensywności uszkodzeń opisanej wzorem (4), gdzie, przyjęto następujące wartości parametrów: $a=1, b=10, c=0,2$. Ich wartość przyjęto tylko w celu pokazania wykresu funkcji. Dla konkretnej funkcji intensywności uszkodzeń parametry te należy wyznaczyć metodą estymacji [np. 1].

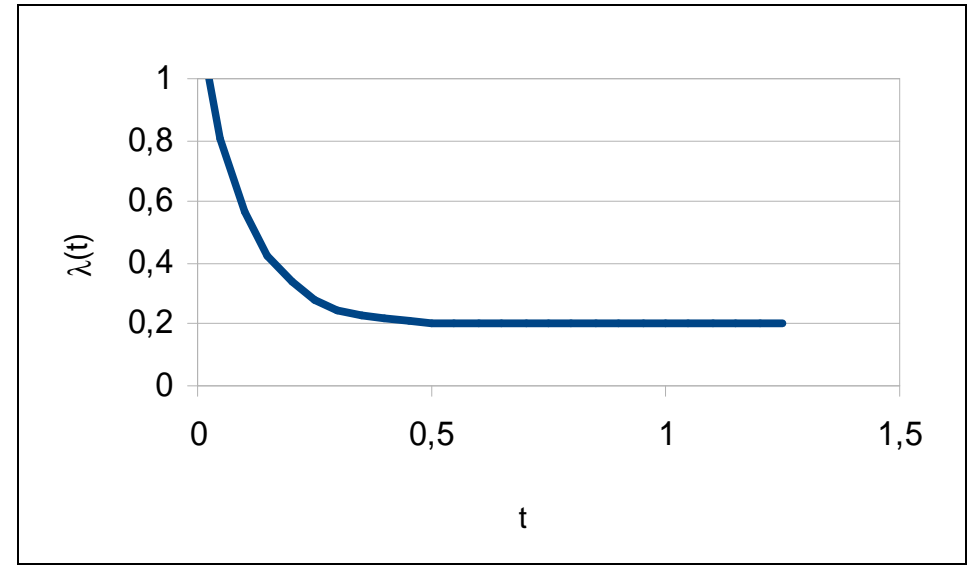

Rys. 1. Wykres funkcji intensywności uszkodzeń. Typ I - malejący. We wzorze (4) przyjęto wartość parametrów: $a=1, b=10 c=0,2$, $\lambda(t)=10 \cdot \mathrm{e}^{-10 t}+0,2$

Fig 1. The graph of the failure rate functions. Type I - decreasing. In the formula (4) following value of the parameter were assumed: $a=1, b=10$, $c=0,2 . \lambda(t)=10 \cdot \mathrm{e}^{-10 t}+0,2$

Jaźwiński i Fiok [4] podają, że ten typ funkcji intensywności uszkodzeń występuje w praktyce dla $68 \%$ przypadków.

\subsection{Typ II - rosnący}

Drugi przypadek wykładniczej zależności to typ rosnący (rys. nr 2). Na początku użytkowania wytworu techniki intensywność uszkodzeń jest stała, a od pewnego czasu, na skutek starzenia, szybko wzrasta. W tym przypadku funkcja intensywności uszkodzeń wyraża się wzorem:

$$
\lambda(t)=a \cdot e^{b t}+c
$$

gdzie: $a, b$ i $c$ są stałymi oraz $a, b, c>0$. 
Na rysunku 2 przedstawiono wykres eksponencjalnej, rosnącej funkcji intensywności uszkodzeń opisanej wzorem (5), gdzie przyjęto parametry: $a=1 \cdot 10^{-6}, b=10, c=0,2$.

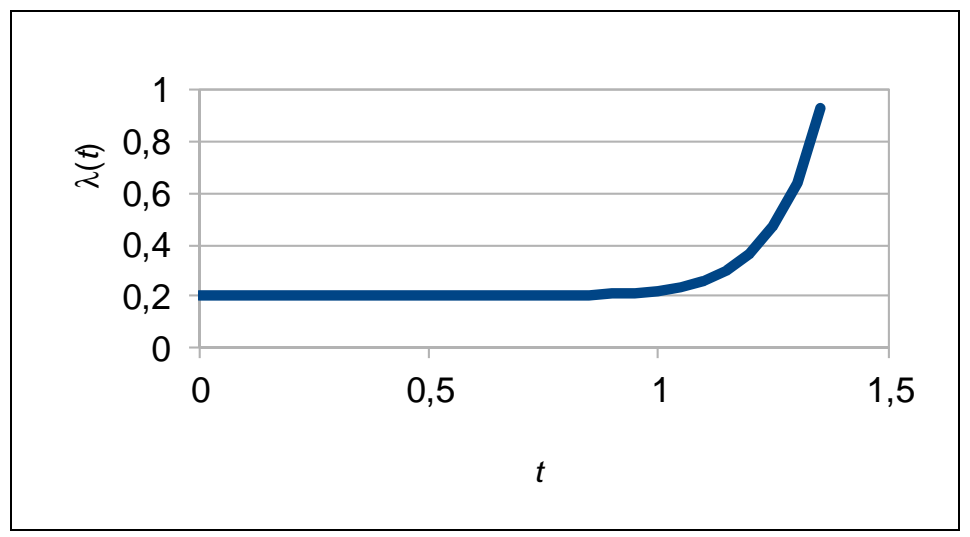

Rys 2. Wykres funkcji intensywności uszkodzeń. Typ II - rosnący. We wzorze (5) przyjęto wartość parametrów: $a=1 \cdot 10^{-6}, b=10, c=0,2$. $\lambda(t)=10^{-6} \cdot \mathrm{e}^{10 t}+0,2$

Fig 2. The graph of the failure rate functions. Type II - increasing. In the formula (5) following value of the parameter were assumed: $a=1 \cdot 10^{-6}$, $b=10, c=0,2 . \lambda(t)=10^{-6} \cdot \mathrm{e}^{10 t}+0,2$

\subsection{Typ III - malejąco-rosnący}

Typ III stanowi połączenie typu I i II. Początkowo intensywność uszkodzeń szybko maleje, następnie utrzymuje stały poziom, aż do osiągnięcia czasu granicznego $T_{G}$, kiedy to następuje zmiana trendu z malejącego na wzrostowy. Początkowo po zmianie trendu występuje okres stabilizacji uszkodzeń, by w końcowym okresie gwałtownie rosnąć. Funkcja intensywności uszkodzeń wyraża się wtedy wzorem:

dla $t<T_{G}$

$$
\lambda(t)=a \cdot e^{-b t}+c
$$

gdzie: $a, b$ i $c$ są stałymi oraz $a, b, c>0$,

dla $t>T_{G}$

$$
\lambda(t)=d \cdot e^{g t}+h
$$

gdzie: $d, g$ i $h$ są stałymi oraz $d, g, h>0$. 
Stała $h$ powinna być tak dobrana, aby funkcja $\lambda(t)$ była ciągła w punkcie $t=T_{G}$, czyli powinien być spełniony warunek:

$$
\begin{aligned}
& a \cdot e^{-b \cdot T_{G}}+c=d \cdot e^{g \cdot T_{G}}+h \\
& h=a \cdot e^{-b \cdot T_{G}}+c-d \cdot e^{g \cdot T_{G}}
\end{aligned}
$$

$\mathrm{Na}$ rysunku 3 przedstawiono wykres eksponencjalnej, malejąco-rosnącej funkcji intensywności uszkodzeń opisanej wzorami $(6,7)$, gdzie przyjęto parametry: $a=1, b=10, c=0,2, d=1 \cdot 10^{-6}, g=10, T_{G}=0,6$. Stała $h$ wyliczona $\mathrm{z}$ warunku (8) wynosi $h=0,202075$.

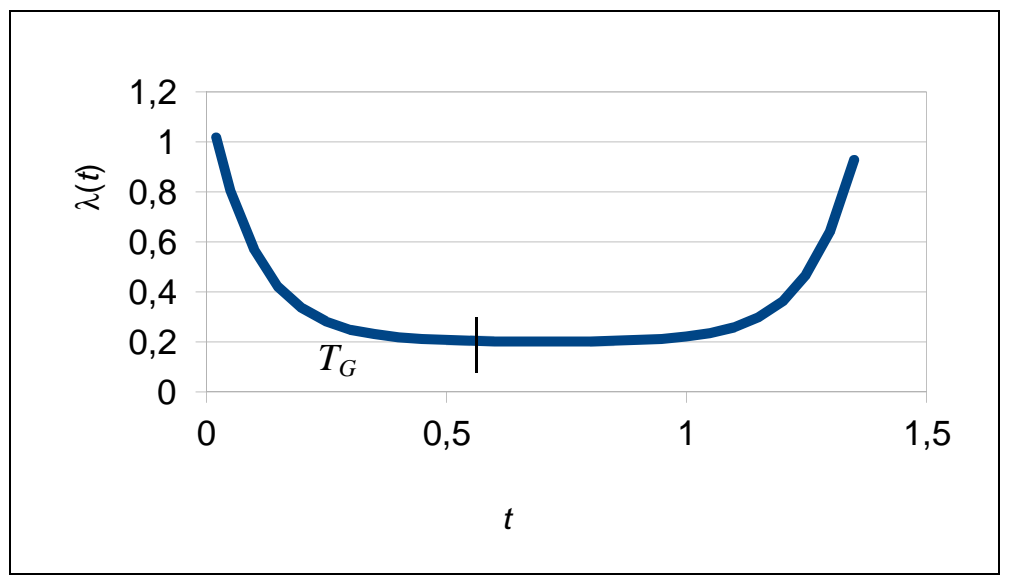

Rys. 3. Wykres funkcji intensywności uszkodzeń. Typ III - malejąco-rosnący. We wzorach $(6,7)$ przyjęto wartość parametrów: $a=1, b=10, c=0,2$, $d=1 \cdot 10^{-6}, g=10, T_{G}=0,6$. Stała $h$ wyliczona $\mathrm{z}$ warunku (8) wynosi $h=0,202075$. Dla $t<T_{G}$ funkcja intensywności uszkodzeń wynosi: $\lambda(t)=10 \cdot \mathrm{e}^{10 t}+0,2$; natomiast dla $t>T_{G}$ wynosi: $\lambda(t)=10^{-6} \cdot \mathrm{e}^{10 t}+0,202075$

Fig 3 . The graph of the failure rate functions. Type III - decreasing-increasing. In formulas $(6,7)$ following value of the parameter were assumed: $a=1, b=10$, $\mathrm{c}=0,2, \mathrm{~d}=1 \cdot 10^{-6}, \mathrm{~g}=10, \mathrm{~T}_{\mathrm{G}}=0,6 . \mathrm{H}$ constant calculated from the condition (8) is $\mathrm{h}=0,202075$. For $\mathrm{t}<\mathrm{TG} \lambda(\mathrm{t})=10 \cdot \mathrm{e}^{10 \mathrm{t}}+0,2$; while for $\mathrm{t}>\mathrm{T}_{\mathrm{G}}$ $\lambda(t)=10-6 \cdot e^{10 t}+0,202075$

Według Szopy [9] jest to typowy, najczęściej występujący w praktyce przebieg funkcji intensywności uszkodzeń. 


\section{Funkcja niezawodności i średni czas bezawaryjnej pracy}

\subsection{Funkcja niezawodności - typ I}

Gdy intensywność uszkodzeń jest typu I, czyli malejąca w czasie, wtedy podstawiając zależność (4) do wzoru (1) i wykonując całkowanie otrzymujemy wzór na funkcję niezawodności:

$$
\begin{aligned}
& R_{I}(t)=\exp \left(\int_{0}^{t}-\lambda(\tau) d \tau\right)=\exp \left[\int_{0}^{t}-\left(a \cdot e^{-b \tau}+c\right) d \tau\right]= \\
& \exp \left[-\left(-\frac{a}{b} e^{-b \tau}+c \tau\right)\right]||_{0}^{t}=\exp \left[\left(\frac{a}{b} e^{-b t}-c t-\frac{a}{b}\right)\right]=\exp \left[\frac{a}{b}\left(e^{-b t}-1\right)-c t\right]
\end{aligned}
$$

Wykres funkcji niezawodności $R(t)$ dla parametrów $a, b, c$ podanych w rozdziale 2.1 i wynoszących: $a=1, b=10 c=0,2$, pokazany jest na rysunku 4 .

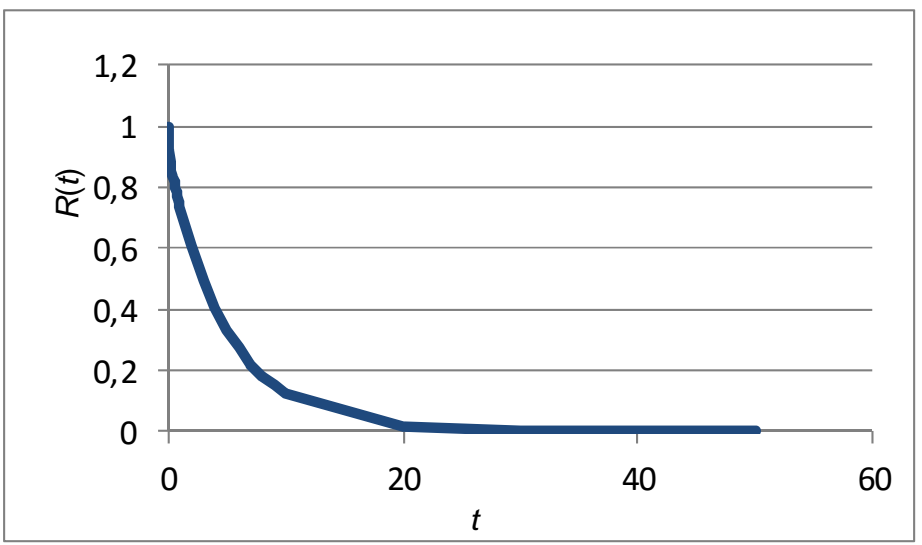

Rys. 4. Wykres funkcji niezawodności $R_{I}(t)$ dla malejącej funkcji intensywności uszkodzeń. Przyjęte parametry wynoszą: $a=1, b=10 c=0,2$. $R_{I}(t)=\exp (0,1(\exp (-10 \cdot t)-1)-0,2 \cdot t)$

Fig. 4 . The graph of the reliability function for decreasing failure rate function Assumed value of the parameter are: $a=1, b=10 c=0,2$. $R_{I}(t)=\exp (0,1(\exp (-10 \cdot t)-1)-0,2 \cdot t)$

\subsection{Obliczenie średniego czasu bezawaryjnej pracy}

Średni czas bezawaryjnej pracy otrzymujemy podstawiając zależność (9) do wzoru (2).

$$
T_{S(I)}=\int_{0}^{\infty} \exp \left[\frac{a}{b}\left(e^{-b t}-1\right)-c t\right] d t
$$


Ponieważ całka (9) nie jest obliczana przez kalkulator całek Wolfram Mathematica [10], wykonujemy następujące przekształcenia. Dokonujemy podstawienia $\mathrm{A}=\mathrm{a} / \mathrm{b}$.

Gdzie wcześniej założono, że b > 0 i wzór (10) przyjmuje postać:

$$
\begin{aligned}
& T_{S(I)}=\int_{0}^{\infty} \exp \left[A\left(e^{-b t}-1\right)\right] \cdot \exp (-c t) d t=\int_{0}^{\infty} \exp \left(A e^{-b t}\right) \cdot e^{-A} \cdot e^{-c t} d t= \\
& e^{-A} \int_{0}^{\infty} \exp \left(A e^{-b t}\right) \cdot e^{-c t} d t
\end{aligned}
$$

Końcową całkę (10) rozwiązujemy metodą podstawienia wprowadzając zmienną $u$.

$$
e^{-c t}=u ; \quad d t=\frac{d u}{-c \cdot u} ; \quad t=\frac{\ln u}{-c}
$$

W granicach 0 i $\infty$ zmienna $u$ przyjmuje następujące wartości:

$$
\begin{aligned}
& \lim _{t \rightarrow 0} u=\lim _{t \rightarrow 0} e^{-c t}=1 \\
& \lim _{t \rightarrow \infty} u=\lim _{t \rightarrow \infty} e^{-c t}=0
\end{aligned}
$$

Po podstawieniu zmiennej $u$ otrzymujemy:

$$
T_{S(I)}=e^{-A} \int_{1}^{0} \exp \left(A e^{-b t}\right) \cdot u \cdot \frac{d u}{-c \cdot u}=-\frac{e^{-A}}{c} \int_{1}^{0} \exp \left(A e^{-b t}\right) d u
$$

Wykorzystujemy ostatnią z formuł (12) oraz zamieniamy granice całkowania

$$
T_{S(I)}=\frac{e^{-A}}{c} \int_{0}^{1} \exp \left(A e^{-b \frac{\ln u}{-c}}\right) d u=\frac{e^{-A}}{c} \int_{0}^{1} \exp \left(A \cdot u^{\frac{b}{c}}\right) d u
$$

Dla otrzymania wzoru (15) wykorzystano poniższą tożsamość (16):

$$
e^{\frac{-b}{-c} \ln u}=e^{\ln u^{\frac{b}{c}}}=u^{\frac{b}{c}}
$$

Wprowadzając $\mathrm{B}=\mathrm{b} / \mathrm{c}$, otrzymujemy:

$$
T_{S(I)}=\frac{e^{-A}}{c} \int_{0}^{1} \exp \left(A u^{B}\right) d u
$$


Całkę (17) już można obliczyć za pomocą kalkulatora Wolfram, który podaje dwa równoważne wyniki:

$$
T_{S(I)}=\frac{e^{-A}}{c}\left[-\left.\frac{u \cdot E_{\frac{B-1}{B}}\left(-A \cdot u^{B}\right)_{1}^{1}}{B}\right|_{0}\right]
$$

a po zamianie granic całkowania

$$
T_{S(I)}=\left.\frac{e^{-A}}{c} \frac{u \cdot E_{\frac{B-1}{B}}\left(-A \cdot u^{B}\right)_{0}}{B}\right|_{1}
$$

gdzie przez $E_{(B-1) / B}$ oznaczono funkcję całki eksponencjalnej zdefiniowanej jako:

$$
E_{n}(z)=\int_{1}^{\infty} \frac{e^{-z t}}{t^{n}} d t .
$$

Drugie rozwiązanie jest postaci:

$$
T_{S(I)}=\frac{e^{-A}}{c}\left[-\left.\frac{u\left(-A u^{B}\right)^{-\frac{1}{B}} \Gamma\left(\frac{1}{B},-A u^{B}\right)_{1}^{1}}{B}\right|_{0}\right]
$$

gdzie przez $\Gamma$ oznaczono funkcję gamma Eulera, której definicja podana jest w wielu podręcznikach matematyki np. [11]. Zgodnie z wcześniejszymi podstawieniami wartość odpowiednich parametrów wynosi:

$$
A=\frac{a}{b} ; \quad B=\frac{b}{c} .
$$

\subsubsection{Rozwiązanie analityczne}

Niestety występują problemy przy obliczeniu obydwu formuł. Na przykład dla stałych $a=1, b=10, c=0,2$ otrzymujemy $A=0,1, B=50$. W granicach całkowania 1 i 0 otrzymujemy $-A \cdot u^{B}=-0,1 \cdot 1^{50}=-0,1$ oraz $-A \cdot u^{B}=-0,1 \cdot 0^{50}=0$. Jak podaje kalkulator Wolfram funkcja eksponencjalna przyjmuje wartość $\mathrm{E}_{0,98}(-0,1)$ $=1.56962-3.25081 \cdot i$ oraz $\mathrm{E}_{0,98}(0)=\infty \cdot i$. Podobny problem występuje przy drugim rozwiązaniu (19). Czynnik $-A \cdot u^{B}<0$ podnoszony jest do potęgi rzeczywistej równej $-1 / B$. W ogólności takie rozwiązanie nie istnieje $\mathrm{w}$ zbiorze liczb rzeczy- 
wistych. A przecież funkcję niezawodności typu I można przedstawić w postaci iloczynu dwóch funkcji:

$$
R_{I}(t)=\exp \left[\frac{a}{b}\left(e^{-b t}-1\right)-c t\right]=\exp \left[\frac{a}{b}\left(e^{-b t}-1\right)\right] \cdot e^{-c t}
$$

Funkcja stanowiąca pierwszy czynnik jest w przedziale $[0, \infty)$ funkcją monotoniczną i ograniczoną bo:

$$
f(t=0)=\exp \left[\frac{a}{b}\left(e^{-b \cdot 0}-1\right)\right]=\exp \left[\frac{a}{b} \cdot 0\right]=1
$$

oraz:

$$
\lim _{t \rightarrow \infty} \exp \left[\frac{a}{b}\left(e^{-b t}-1\right)\right]=\exp \left[\frac{a}{b}(0-1)\right]=e^{-\frac{a}{b}} .
$$

Jednocześnie drugi składnik jest funkcją całkowalną w przedziale $(0, \infty)$, gdyż:

$$
\int_{0}^{\infty} e^{-c t} d t=-\left.\frac{1}{c} e^{-c t}\right|_{0} ^{\infty}=0+\frac{1}{c}=\frac{1}{c} .
$$

Zatem, na mocy kryterium Abela [3] istnieje całka z funkcji $R_{I}(t)$ w granicach $[0, \infty)$ i jako pole pod wykresem nr 1 powinna wyrażać się skończoną liczbą rzeczywistą.

\subsubsection{Rozwiązanie numeryczne}

Z puntu widzenia praktyki inżynierskiej najważniejsze jest otrzymanie liczbowej wartości średniego czasu bezawaryjnej pracy. Techniczne szczegóły obliczeń matematycznych nie są dla inżyniera istotne. Dlatego średni czas bezawaryjnej pracy można obliczyć stosując metody całkowania numerycznego. W tym celu wykorzystano program otwartej licencji QtOctave [6] dostępny w każdej dystrybucji Linuxa Ubuntu. Aby obliczyć wartość całki oznaczonej określonej wzorem (10) należy w powyższym programie wykonać następujące komendy:

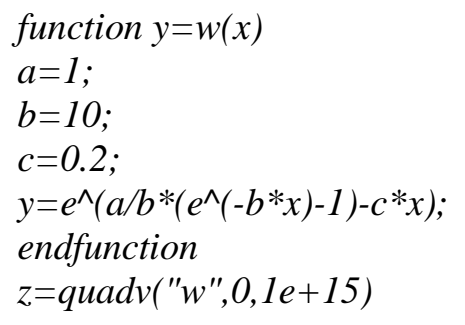


Stałe $a, b, c$ przyjęto zgodnie z podanymi wartościami w rozdziale 2.3. Górną granicę całkowania wynoszącą $\infty$ przyjęto równą $10^{15}$. Jako rezultat otrzymano wartość: 4,5333. Bardzo zbliżony rezultat otrzymuje się przy zastosowaniu zwykłego arkusza kalkulacyjnego. Stosując metodę trapezów oraz zmienną długość przedziału całkowania, podaną w tab. 1 otrzymujemy wartość całki równą 4,5386.

Tabela. 1. Przyjęte przedziały całkowania numerycznego metodą trapezów

Table. 1. Assumed ranges for numerical integration using the trapezoidal method

\begin{tabular}{|c|c|c|}
\hline od & do & długość przedziału \\
\hline 0 & 0,01 & 0,001 \\
\hline 0,01 & 0,1 & 0,01 \\
\hline 0,1 & 1 & 0,1 \\
\hline 1 & 10 & 1 \\
\hline 10 & 100 & 10 \\
\hline 100 & 1000 & 100 \\
\hline
\end{tabular}

Różnica wynosi zaledwie 1\%o, co z punktu widzenia inżynierskiego jest wielkością nieistotną. Czyli całkowanie można bez utraty dokładności wykonać w zwykłym arkuszy kalkulacyjnym. A jest to narzędzie dostępne każdemu inżynierowi.

\subsection{Funkcja niezawodności - typ II}

Gdy intensywność uszkodzeń jest typu II wtedy podstawiając zależność (5) do wzoru (1) i wykonując całkowanie otrzymujemy wzór na funkcję niezawodności:

$$
\begin{aligned}
& R_{I I}(t)=\exp \left(\int_{0}^{t}-\lambda(\tau) d \tau\right)=\exp \left[\int_{0}^{t}-\left(a \cdot e^{b \tau}+c\right) d \tau\right]= \\
& \exp \left[-\left.\left(\frac{a}{b} e^{b \tau}+c \tau\right)\right|_{0} ^{t}\right]=\exp \left[-\frac{a}{b} e^{b t}+\frac{a}{b}-c t\right]=\exp \left[-\frac{a}{b}\left(e^{b t}-1\right)-c t\right]
\end{aligned}
$$

Wykres funkcji niezawodności $R_{I I}(t)$ dla parametrów podanych w rodz. 2.3 i wynoszących: $a=1 \cdot 10^{-6}, b=10, c=0,2$ prezentuje rysunek 5 . 


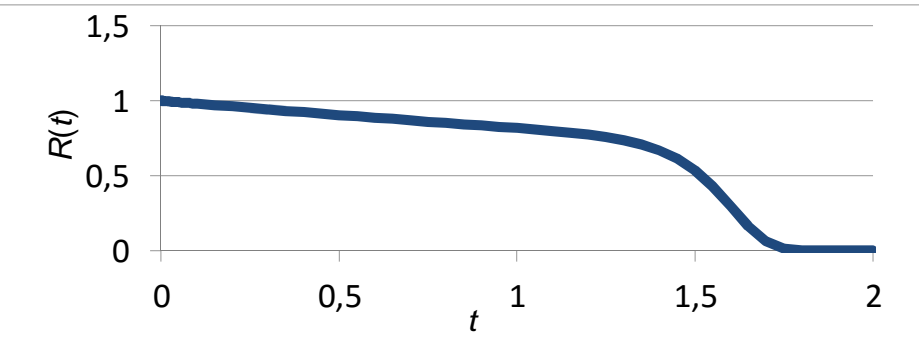

Rys. 5. Wykres funkcji niezawodności $R_{\mathrm{II}}(t)$ dla rosnącej funkcji intensywności uszkodzeń, przyjęte parametry wynoszą: $a=1 \cdot 10^{-6}, b=10, c=0,2$. $R_{\mathrm{II}}(t)=\exp \left(-10^{-7}(\exp (10 \cdot t-1)-0,2 \cdot t)\right.$

Fig. 5. The graph of the reliability function for increasing failure rate function Assumed value of the parameter are: $a=1 \cdot 10^{-6}, b=10, c=0,2$. $R_{\mathrm{II}}(t)=\exp \left(-10^{-7}(\exp (10 \cdot t-1)-0,2 \cdot t)\right.$

\subsection{Obliczenie średniego czasu bezawaryjnej pracy}

Średni czas bezawaryjnej pracy otrzymujemy podstawiając zależność (20) do wzoru (2).

$$
T_{S(I I)}=\int_{0}^{\infty} \exp \left[-\frac{a}{b}\left(e^{b t}-1\right)-c t\right] d t
$$

Całką obliczymy wykonując analogiczne przekształcenia i podstawienia jak w poprzednim rozdziale.

$$
\begin{aligned}
& A=\frac{a}{b} ; \quad T_{S(I I)}=\int_{0}^{\infty} \exp \left[-A\left(e^{b t}-1\right)\right] \cdot \exp (-c t) d t=\int_{0}^{\infty} \exp \left(-A e^{b t}\right) \cdot e^{A} \cdot e^{-c t} d t= \\
& e^{A} \int_{0}^{\infty} \exp \left(-A e^{b t}\right) \cdot e^{-c t} d t
\end{aligned}
$$

podstawiamy

$$
e^{-c t}=u ; \quad d t=\frac{d u}{-c \cdot u} ; \quad t=\frac{\ln u}{-c},
$$

obliczamy granice

i otrzymujemy:

$$
\begin{aligned}
& \lim _{t \rightarrow 0} u=\lim _{t \rightarrow 0} e^{-c t}=1 \\
& \lim _{t \rightarrow \infty} u=\lim _{t \rightarrow \infty} e^{-c t}=0
\end{aligned}
$$

$$
T_{S(I I)}=e^{A} \int_{1}^{0} \exp \left(-A e^{-b t}\right) \cdot u \cdot \frac{d u}{-c \cdot u}=\frac{e^{A}}{-c} \int_{1}^{0} \exp \left(-A e^{-b t}\right) d u .
$$


Zamieniamy zmienną $t$, granice całkowania oraz podstawiamy

$$
\begin{aligned}
& B=\frac{b}{c} \\
& T_{S(I I)}=\frac{e^{A}}{c} \int_{0}^{1} \exp \left(-A e^{-b \frac{\ln u}{-c}}\right) d u=\frac{e^{A}}{c} \int_{0}^{1} \exp \left(-A \cdot u^{\frac{b}{c}}\right) d u= \\
& \frac{e^{A}}{c} \int_{0}^{1} \exp \left(-A \cdot u^{B}\right) d u .
\end{aligned}
$$

Jako wynik całkowania Wolfram Mathematica [10] podaje:

$$
T_{S(I I)}=\frac{e^{A}}{c}\left[-\left.\frac{u}{B} E_{\frac{B-1}{B}}\left(A \cdot u^{B}\right)\right|_{0} ^{1}\right]=-\frac{e^{A}}{c} \frac{u}{B} E_{\frac{B-1}{B}}\left(A \cdot u^{B}\right)_{0}^{1}
$$

oraz formę alternatywną,

$$
T_{S(I I)}=-\left.\frac{e^{A}}{c} \frac{A^{\frac{-1}{B}}}{B} \Gamma\left(\frac{1}{B}, A \cdot u^{B}\right)\right|_{0} ^{1}
$$

gdzie $A, B$ i $u$ ma być nieujemne, co w rozważanym przypadku jest spełnione.

\subsubsection{Rozwiązanie analityczne}

Podobnie jak w poprzednim przypadku występują kłopoty z zastosowaniem wzoru (22), gdyż kalkulator funkcji [10] podaje wartość nieskończoną dla $u=0$. Natomiast zastosowanie wzoru (23) prowadzi do wyniku będącego liczbą rzeczywistą. Na przykład dla stałych $a=10^{-6}, b=10, c=0,2$ otrzymujemy następujące wyniki

$$
\begin{aligned}
& A=10^{-7}, \quad B=50, \quad A^{\frac{-1}{B}}=1,3804, \quad \frac{A^{\frac{-1}{B}}}{B}=0,0276, \quad-\frac{e^{A}}{c}=-5,0 \\
& \frac{1}{B}=0,02, \quad-\frac{e^{A}}{c} \frac{A^{-\frac{1}{B}}}{B}=0,138 .
\end{aligned}
$$

Wartość funkcji $\Gamma$ w granicach całkowania $(0 ; 1)$ wynosi odpowiednio:

dla $u=0$

$$
\Gamma(0,02 ; 0)=49,4422
$$

dla $\mathrm{u}=1$

$$
A \cdot u^{B}=10^{-7}, \quad \Gamma\left(0,02 ; 10^{-7}\right)=13,2204 .
$$


Czyli $T_{S}$ wynosi

$$
T_{S}=-0,138 \cdot(13,2204-49,4422)=4,9986 .
$$

Co patrząc na wykres funkcji niezawodności (rys. 5) wydaje się być wartością nierealną.

\subsubsection{Rozwiązanie numeryczne}

Rozwiązanie numeryczne, tak jak poprzednio zostało wykonane za pomocą programu QtOcatve oraz metodą trapezów i arkusz kalkulacyjnego. W programie QtOctave wykonano następujące instrukcje:

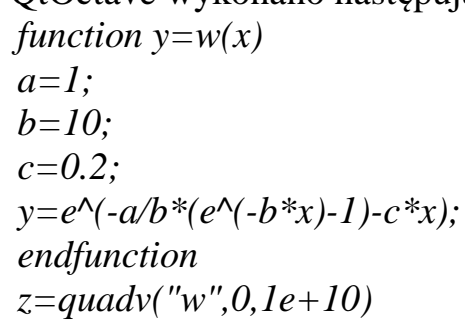

i otrzymano wynik $T_{S}=1,3345$. Identyczny rezultat uzyskuje się stosując metodę trapezów i krok całkowania 0,05. Różnica wyników uzyskanych w tym i poprzednim rozdziale jest zaskakująco duża.

\subsection{Funkcja intensywności uszkodzeń typ III}

W przypadku, gdy intensywność uszkodzeń ma charakter malejąco rosnący wzór, jakim wyraża się funkcja intensywności uszkodzeń zależy od górnej granicy całkowania. Gdy $t<T_{G}$, wtedy

$$
\begin{aligned}
& R_{I I I}(t)=\exp \left(\int_{0}^{t}-\lambda(\tau) d \tau\right)=\exp \left[\int_{0}^{t}-\left(a \cdot e^{-b \tau}+c\right) d \tau\right]= \\
& \exp \left[\left.\left(\frac{a}{b} e^{-b \tau}-c \tau\right)\right|_{0} ^{t}\right]=\exp \left[\frac{a}{b} e^{-b t}-\frac{a}{b}-c t\right]= \\
& \exp \left[\frac{a}{b}\left(e^{-b t}-1\right)-c t\right] .
\end{aligned}
$$

Natomiast gdy $t>T_{G}$, wtedy 


$$
\begin{aligned}
& R_{I I I}(t)=\exp \left(\int_{0}^{t}-\lambda(\tau) d \tau\right)=\exp \left[\int_{0}^{T_{G}}-\left(a \cdot e^{-b \tau}+c\right) d \tau+\int_{T_{G}}^{\infty}-\left(d \cdot e^{g \tau}+h\right) d \tau+\right]= \\
& \exp \left[\left.\left(\frac{a}{b} e^{-b \tau}-c \tau\right)\right|_{0} ^{T_{G}}+\left.\left(-\frac{d}{g} e^{g \tau}-h \tau\right)\right|_{T_{G}} ^{t}\right]= \\
& \exp \left[\frac{a}{b} e^{-b T_{G}}-\frac{a}{b}-c T_{G}-\frac{d}{g} e^{g t}-g t+\frac{d}{g} e^{g T_{G}}+h T_{G}\right]= \\
& \exp \left[K-\left(\frac{d}{g} e^{g t}+h t\right)\right]
\end{aligned}
$$

gdzie

$$
K=\frac{a}{b} e^{-b T_{G}}-\frac{a}{b}-c T_{G}+\frac{d}{g} e^{g T_{G}}+h T_{G}
$$

oraz stałe $a, b, c, d, g, h>0$.

Funkcję niezawodności typu III odpowiadającej malejąco-rosnącej intensywności uszkodzeń dla parametrów $a=1, b=10, c=0,2, d=1 \cdot 10^{-6}, g=10$, $h=0,202075$ oraz $T_{G}=0,6$ prezentuje rysunek $\mathrm{nr} 6$. Wartości parametrów zostały przyjęte dowolnie, w celu wykonania wykresu. Dla rzeczywistego problemu, wartości charakteryzujące funkcję intensywności uszkodzeń należy obliczać metodą estymacji [np. 1]. W omawianym przypadku stała $K$ zdefiniowana wzorem (26) wynosi $K=-0,098467$.

\subsection{Obliczenie średniego czasu bezawaryjnej pracy}

Średni czas bezawaryjnej pracy otrzymujemy podstawiając wzór (24) i (25) do wzoru (2):

$$
T_{S}=\int_{0}^{T_{G}} \exp \left[\frac{a}{b}\left(e^{-b t}-1\right)-c t\right] d t+\int_{T_{G}}^{\infty} \exp \left[K-\left(\frac{d}{g} e^{g t}+h t\right)\right] d t .
$$

\subsubsection{Rozwiązanie analityczne}

Z przyczyn podanych $w$ rozdziale 3.2.1. nie da się w analityczny sposób policzyć pierwszego członu całki (27), a w rozdziale 3.4.1 wykazano niepoprawność obliczeń drugiego członu całki za pomocą kalkulatora Wolfram [10]. Dlatego trzeba posłużyć się rozwiązaniem numerycznym. 


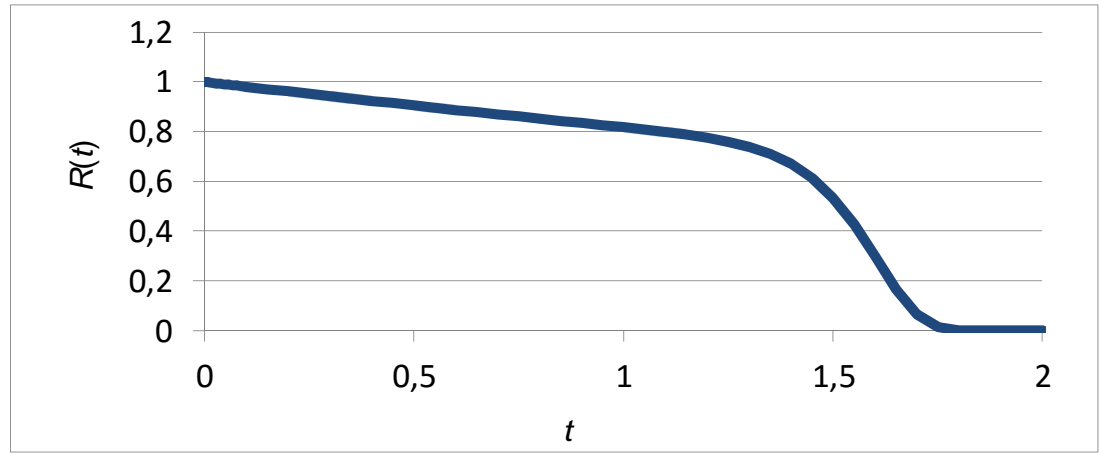

Rys. 6. Wykres funkcji niezawodności $R_{I I I}(t)$ dla malejąco-rosnącej funkcji intensywności uszkodzeń. Przyjęte wartości parametrów wynoszą: $a=1, b=10, c=0,2, d=1 \cdot 10^{-6}$, $g=10, h=0,202075$ oraz $T_{G}=0,6$. Funkcja niezawodności wynosi: $R_{I I I}(t)=$ $\exp (0,1(\exp (-10 \cdot t)-1)-0,2 \cdot t)$ dla $t<0,6$ oraz $R_{I I I}(t)=\exp \left(-10^{-7}(\exp (10 \cdot t-1)-0,202075 \cdot t) \mathrm{dla}\right.$ $\mathrm{t}>0,6$.

Fig. 6. The graph of the reliability function for decreasing-increasing failure rate function. Assumed value of the parameter are $a=1, b=10, c=0,2, d=1 \cdot 10^{-6}, g=10$, $h=0,202075$ and $T_{G}=0,6$. The reliability function is: $R_{I I I}(t)=\exp (0,1(\exp (-10 \cdot t)-1)-0,2 \cdot t)$ for $t<0,6$ while $R_{\text {III }}(t)=\exp \left(-10^{-7} \cdot(\exp (10 \cdot t-1)-0,202075 \cdot t)\right.$ for $\mathrm{t}>0,6$.

\subsubsection{Rozwiązanie numeryczne}

Zastosowana w arkuszu kalkulacyjnym metoda trapezów z krokiem całkowania 0,05 daje rezultat $T_{S}=1,21640$.

W programie QtOctave [6] należy wykonać dwie operacje dla każdej całki oddzielnie, a następnie zsumować wynik.

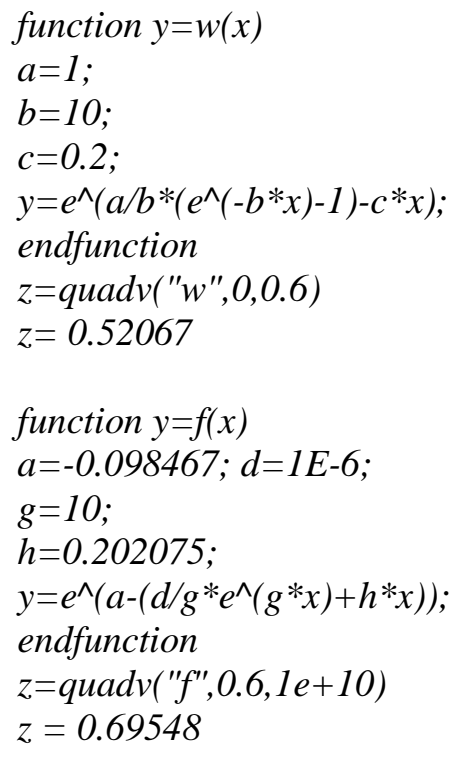


Sumując otrzymane wartości otrzymuje się wynik $T_{S}=1,216$. Różnica pomiędzy wynikami uzyskanymi za pomocą QtOctave [6] oraz arkusza kalkulacyjnego wynosi $0,2 \%$.

\section{Wnioski}

Należy zwrócić uwagę na dwa uzyskane rezultaty:

1) w przypadku całek wykładniczych o podstawie $e$, kalkulator całek [10] najprawdopodobniej nie daje poprawnych rezultatów, gdyż obliczona w rozdziale 3.4.1 metodą analityczną wartość średniego czasu bezawaryjnej pracy jest wielkością niepoprawną. Możliwe jest także ze kalkulator funkcji specjalnych daje niepoprawne wartości. Wydaje się jednak, że ze względu na fakt stosowania funkcji specjalnych od XIX w i istniejące tablice ich wartości opcja ta jest mniej prawdopodobna;

2) różnice pomiędzy średnimi czasami bezawaryjnej pracy obliczonymi specjalistycznym programem do całkowania numerycznego QtOctave [9], a obliczeniami metodą trapezów przeprowadzoną za pomocą zwykłego arkusza kalkulacyjnego nie przekraczają $1 \%$ wartości. W przypadku inżynierskim jest to dokładność wystraczająca. Zatem w celu obliczenia średniego, bezawaryjnego czasu pracy, nie ma konieczności wykonywania skomplikowanych całek wykładniczych, bądź sięgania po i uczenia się obsługi specjalistycznych programów komputerowych. W tym celu wystarczy obliczyć stosunkowo prostą całkę (1), której rozwiązania można znaleźć w tablicach całek [np.2, 8], a w celu obliczenia wartości całki (2) zastosować arkusz kalkulacyjny i powszechnie znaną metodę trapezów.

Podziękowania

Składam serdeczne podziękowania Pani dr hab. prof. AGH Annie Barańskiej za sprawdzenie obliczeń i zwrócenie mi uwagi na błędy i nieścisłości.

\section{Literatura}

[1] Bajer J., Iwanejko R., Kapcia J., Niezawodność systemów wodociągowych i kanalizacyjnych w zadaniach, Politechnika krakowska, Kraków 2006 r.

[2] Dwight H.B., Tables of integrals and other mathematical data, (wydanie rosyjskie), Moskwa 1973 r.

[3] Fichtenholz G.M., Rachunek różniczkowy i całkowy, T2, PWN, Warszawa, 1972 r.

[4] Jaźwiński J., Warzyńska-FiokK., Bezpieczeństwo systemów, PWN, Warszawa 1993.

[5] Opyrchał L., Funkcja niezawodności i czas bezawaryjnej pracy odpowiadający liniowej intensywności uszkodzeń, Czasopismo Inżynierii Lądowej, Środowiska i Architektury, T. XXXI, z. 61, 2014 r. str. 173-182

[6] QtOctave, http://www.gnu.org/software/octave/, 12.01.2015 r. 
[7] Rak J.R. (red), Kwietniewski M., Kowalski D., Tchórzewska-Cieślak B., Zimoch I., Bajer J., Iwanejko R., Miszta-Kruk K., Studziński A., Boryczko K., PietruchaUrbanik K., Piegoń I., Metody oceny niezawodności i bezpieczeństwa dostawy wody do odbiorców, Oficyna Wydawnicza Politechniki Rzeszowskiej, Rzeszów 2013.

[8] Ryżyk I.M., Gradsztejn I.S., Tablice całek sum, szeregów i iloczynów, PWN, Warszawa 1964 r.

[9] Szopa T., Niezawodność i bezpieczeństwo. Oficyna Wydawnicza Politechniki Warszawskiej, Warszawa, 2009 r.

[10] Wolfram Mathematica, www.wolframalfa.com, 12.01.2015 r.

[11] Whittaker E.T., Watson G.N., Kurs analizy współczesnej, T2, PWN, Warszawa 1968.

\section{THE RELIABILITY FUNCTION AND ERROR FREE RUNNING TIME RESPECTIVE TO THE EXPONENTIAL FAILURE RATE}

\section{S u m m a r y}

The reliability function plays a fundamental role in the reliability, as it allows to calculate the probability of failure in a given time $t$. To calculate the reliability function is necessary to calculate the integral of the failure rate function. In current practice, the calculation of reliability failure rate function is used, which is constant in time. At the same time given that the failure rate is not constant over time. The simplest case of linear dependence of the intensity function of time, damage has already been solved. As pointed out by many authors, the intensity of the damage is the exponential function of time. Therefore, this article explains how the calculations of the reliability and error free running time in the case where the failure rate varies with time exponentially. There are three cases. First, when the function is decreasing failure rate then stood at the time. Such dependence occurs at the beginning of the product. The second case is when the beginning of the function failure rate is stable over time and then rapidly grows. This relationship corresponds to the final phase of the product. The third case is a combination of the first two. It is decreasing at the beginning of use, and then was finally increased when the lifetime of the product ends. As a result of calculations obtained analytical formulas for the reliability function $R$ and the error free running time $T_{S}$. It has been shown that in order to calculate the error free running time need neither calculate integrals, nor to use special software. Just to calculate the corresponding integrals of the method of trapezoids and plain spreadsheet. Committed in this case, the error is less than $1 \%$. There is to engineers a sufficient accuracy.

Keywords: reliability function, error free running time, failure rate, exponential function

Przestano do redakcji: 23.05.2015 $r$.

Przyjęto do druku: 30.10.2015 r.

DOI: $10.7862 / \mathrm{rb} .2015 .116$ 